\title{
Tamanho de parcela e número de repetições em canola
}

\author{
Alberto Cargnelutti Filho (*); Bruna Mendonça Alves; Cláudia Burin; \\ Jéssica Andiara Kleinpaul; Daniela Lixinski Silveira; Fernanda Martins Simões \\ Universidade Federal de Santa Maria (UFSM), Departamento de Fitotecnia, \\ Avenida Roraima, 1000, 97105-900 Santa Maria (RS), Brasil. \\ $\left({ }^{*}\right)$ Autor correspondente: alberto.cargnelutti.filho@gmail.com
}

Recebido: 26/nov./2014; Aceito: 13/fev./2015

\section{Resumo}

Os objetivos deste trabalho foram determinar o tamanho ótimo de parcela e o número de repetições, para avaliar a massa verde de canola (Brassica napus L.). Foram realizados 27 ensaios de uniformidade de $5 \mathrm{~m} \times 5 \mathrm{~m}\left(25 \mathrm{~m}^{2}\right)$, sendo nove ensaios para cada um dos seguintes híbridos: Hyola 61, Hyola 76 e Hyola 433. Cada ensaio foi dividido em 25 unidades experimentais básicas (UEB) de $1 \mathrm{~m} \times 1 \mathrm{~m}$, totalizando 675 UEB. Foi pesada a massa verde das plantas de cada UEB. O tamanho ótimo de parcela (Xo) foi determinado por meio do método da curvatura máxima do modelo do coeficiente de variação, e as comparações de médias, entre os híbridos, foram feitas pelo teste de Scott-Knott. O número de repetições, para experimentos nos delineamentos inteiramente casualizados e blocos ao acaso, em cenários formados pelas combinações de i tratamentos (i=3, 4, ..., 50) e d diferenças mínimas entre médias de tratamentos a serem detectadas como significativas a 5\% de probabilidade, pelo teste de Tukey, expressas em percentagem da média do experimento ( $d=10 \%, 13 \%, \ldots, 40 \%)$, foi determinado por processo iterativo até a convergência. 0 tamanho ótimo de parcela para avaliar a massa verde de canola é $6,41 \mathrm{~m}^{2}$. Quatro repetições, para avaliar até 50 tratamentos, nos delineamentos inteiramente casualizados e blocos ao acaso, são suficientes para identificar, como significativas a 5\% de probabilidade, pelo teste de Tukey, diferenças entre médias de tratamentos de 41,4\% da média do experimento.

Palavras-chave: Brassica napus L., experimentação agrícola, planejamento experimental, precisão experimental.

\section{Plot size and number of repetitions in canola}

\section{Abstract}

The objectives of this work were to determine the optimum plot size and number of repetitions, to evaluate the fresh weight of canola (Brassica napus L.). Twenty-seven uniformity trials of $5 \mathrm{~m} \times 5 \mathrm{~m}\left(25 \mathrm{~m}^{2}\right)$ were conducted. Each trials was divided in 25 basic experimental units (BEU) of $1 \mathrm{~m} \times 1 \mathrm{~m}$, totaling 675BEU. The fresh weight of plants, in each BEU was weighed. The optimum plot size (Xo) was determined by the method of maximum curvature of the model coefficient of variation and the means compared, among hybrids, by Scott-Knott test. The number of repetitions, for experiments on completely randomized and randomized block designs, in scenarios of combinations of i treatments $(i=3,4, \ldots, 50)$ and d minimal differences between treatments means, to be detected as significant, $5 \%$ probability by Tukey test, expressed in percentage of the average of the experiment ( $d=10 \%$, $12 \%, \ldots, 40 \%)$, was determined by iterative process until convergence. The optimum plot size to evaluate the fresh weight of canola is $6.41 \mathrm{~m}^{2}$. Four replications, to evaluate up to 50 treatments, in completely randomized and randomized block designs, are sufficient to identify, as significant at the $5 \%$ probability by Tukey test, differences between treatment means $41.4 \%$ of the average experiment.

Key words: Brassica napus L., agricultural experimentation, experimental design, experimental precision.

\section{INTRODUÇÃO}

A canola (Brassica napus L.) é uma planta oleaginosa desenvolvida a partir do melhoramento genético da colza (Kaefer et al., 2014; Tomm et al., 2009). É destinada a produção de grãos e de óleo comestível e biodiesel, e seu resíduo é usado na fabricação de rações para alimentação animal (Mori et al., 2014; Tomm et al., 2009). Também é cultivada como adubo verde de inverno (Mori et al., 2014;
Pavinato et al., 1994), em sistema de rotação de culturas. Nesse cenário, em experimentos com a cultura de canola, além da produtividade de grãos e do teor de óleo, o dimensionamento da quantidade de massa verde e/ou de massa seca de parte aérea é importante para avaliar o potencial da espécie como cobertura de solo. 
$\mathrm{Na}$ cultura de canola, aspectos relacionados à produtividade de gráos e/ou teor de óleo têm sido avaliados em pesquisas desenvolvidas por Bandeira et al. (2013), Kaefer et al. (2014), Krüger et al. (2011), Luz et al. (2013) e Sanches et al. (2014). Além desses dois caracteres, a massa seca e/ou massa verde de parte aérea de canola tem sido dimensionada em pesquisas de Bandeira et al. (2013), Castro \& Boaretto (2004), Kaefer et al. (2014), Pavinato et al. (1994) e Sanches et al. (2014). Nessas pesquisas, as avaliaçốes desses caracteres foram realizadas em parcelas experimentais com distintas dimensôes, e os experimentos foram em delineamento blocos ao acaso com quatro repetiçóes. De maneira geral, nesses estudos têm sido apontadas características promissoras da cultura de canola.

$\mathrm{Na}$ avaliação da massa verde de parte aérea de canola/colza (Brassica napus L.), Pavinato et al. (1994) coletaram amostras de $1 \mathrm{~m}^{2}$ de cada parcela e retiraram uma subamostra para determinar a massa seca. Para determinar os efeitos da população de plantas nos teores de nutrientes de canola, Castro $\&$ Boaretto (2004) utilizaram parcelas de $12 \mathrm{~m}^{2}(3 \mathrm{~m} \times 4 \mathrm{~m})$ com área útil de $6 \mathrm{~m}^{2}, 12,96 \mathrm{~m}^{2}(3,24 \mathrm{~m} \times 4 \mathrm{~m})$ com área útil de $6,48 \mathrm{~m}^{2}$ e $14,4 \mathrm{~m}^{2}(3,6 \mathrm{~m} \times 4 \mathrm{~m})$ com área útil de $6,48 \mathrm{~m}^{2}$. Já no estudo de arranjo de plantas dos híbridos de canola Hyola 432 e Hyola 61, realizado por Krüger et al. (2011), foram utilizadas parcelas de $5,0 \mathrm{~m}^{2}(1 \mathrm{~m} \times 5 \mathrm{~m}), 10,0 \mathrm{~m}^{2}(2 \mathrm{~m} \times 5 \mathrm{~m})$ e $15,0 \mathrm{~m}^{2}(3 \mathrm{~m} \times 5 \mathrm{~m})$.

Parcelas de $6,8 \mathrm{~m}^{2}(1,36 \mathrm{~m} \times 5 \mathrm{~m}), 10,2 \mathrm{~m}^{2}(2,04 \mathrm{~m} \times 5 \mathrm{~m}) \mathrm{e}$ $13,6 \mathrm{~m}^{2}(2,72 \mathrm{~m} \times 5 \mathrm{~m})$ foram utilizadas por Bandeira et al. (2013), com a finalidade de avaliar o desempenho agronômico de canola em espaçamentos entrelinhas e densidades de plantas. Para a mensuração da produtividade de grãos dos híbridos de canola: Hyola 61, Hyola 433, Hyola 43, Hyola 60 e Hyola 432, parcelas de $11,25 \mathrm{~m}^{2}(2,25 \mathrm{~m} \times 5 \mathrm{~m})$ e área útil de $5,4 \mathrm{~m}^{2}(1,35 \mathrm{~m} \times 4 \mathrm{~m})$ foram utilizadas por Luz et al. (2013). Parcelas de $15,3 \mathrm{~m}^{2}(2,55 \mathrm{~m} \times 6 \mathrm{~m})$, com área útil de $5,0 \mathrm{~m}^{2}$, foram usadas para avaliar a resposta de canola (híbrido Hyola 61) a fontes e doses de nitrogênio (Kaefer et al., 2014). Visando dimensionar a massa seca da parte aérea de canola (híbrido Hyola 61) sob irrigação e doses de adubação nitrogenada, Sanches et al. (2014) utilizaram parcelas de $5,4 \mathrm{~m}^{2}(1,8 \mathrm{~m} \times 3 \mathrm{~m})$, sendo as avaliaçôes realizadas em área útil de $1,8 \mathrm{~m}^{2}(0,9 \mathrm{~m} \times 2 \mathrm{~m})$.

Em culturas agrícolas com potencial para cobertura de solo, é importante quantificar, com precisão, a quantidade de massa verde de parte aérea. Para isso, planejamentos experimentais, com adequado dimensionamento de tamanho ótimo de parcela e número de repetiçóes, são fundamentais para obtenção de resultados fidedignos. A partir de dados obtidos em ensaios de uniformidade (experimentos sem tratamentos, em que a cultura agrícola e todos os procedimentos realizados durante o experimento são homogêneos em toda a área experimental), é possível determinar o tamanho ótimo de parcela e o número de repetiçóes. Dimensionamentos do tamanho ótimo de parcela, com base no método da curvatura máxima do modelo do coeficiente de variaçáo
(Paranaíba et al., 2009), e do número de repetiçốes em combinaçóes de tratamentos e níveis de precisão, têm sido realizados para a mensuração da massa verde de aveia preta (Avena strigosa Schreb) (Cargnelutti et al., 2014a) e para massa verde de vagens, massa verde de parte aérea sem vagens e massa verde de parte aérea de feijão-de-porco (Canavalia ensiformis) (Cargnelutti et al., 2014b). No entanto, em outras plantas com potencial de cobertura de solo, como a canola, investigaçóes sobre o tamanho ótimo de parcela e o número de repetições, para avaliar a massa verde de parte aérea, não foram encontradas na literatura. Assim, os objetivos deste trabalho foram determinar o tamanho ótimo de parcela e o número de repetiçóes, para avaliar a massa verde de canola (Brassica napus L.).

\section{MATERIAL E MÉTODO}

Foram conduzidos 27 ensaios de uniformidade com a cultura de canola (Brassica napus L.), em área experimental localizada a $29^{\circ} 42^{\prime} \mathrm{S}, 53^{\circ} 49^{\prime} \mathrm{W}$ e a $95 \mathrm{~m}$ de altitude. Desses 27 ensaios de uniformidade, 9 foram com o híbrido Hyola 61, 9 com o híbrido Hyola 76 e os outros 9 com o híbrido Hyola 433. Conforme classificação de Köppen, o clima da região é do tipo Cfa, subtropical úmido, com veróes quentes e sem estação seca definida (Heldwein et al., 2009). O solo é classificado como Argissolo Vermelho distrófico arênico (Santos et al., 2006).

Nos 27 ensaios de uniformidade, a semeadura foi realizada em linhas, com espaçamento de $0,50 \mathrm{~m}$ entrelinhas, no dia 13/6/2013, com emergência das plantas em 20/6/2013. A adubação de base foi de $8 \mathrm{~kg} \mathrm{ha}^{-1}$ de $\mathrm{N}, 80 \mathrm{~kg} \mathrm{ha}^{-1}$ de $\mathrm{P}_{2} \mathrm{O}_{5}$ e $80 \mathrm{~kg} \mathrm{ha}^{-1}$ de $\mathrm{K}_{2} \mathrm{O}$. Cada ensaio de uniformidade de tamanho $5 \mathrm{~m} \times 5 \mathrm{~m}\left(25 \mathrm{~m}^{2}\right)$ foi dividido em 25 unidades experimentais básicas (UEB) de $1 \mathrm{~m} \times 1 \mathrm{~m}\left(1 \mathrm{~m}^{2}\right)$, formando uma matriz de cinco linhas e cinco colunas. Aos 127 dias após a semeadura, em cada UEB, foram cortadas as plantas, junto à superfície do solo, e pesada a massa verde em gramas $\mathrm{m}^{-2}$, e contado o número de plantas. Por meio dessa contagem, a densidade obtida foi de 320.267, 351.067 e 410.800 plantas $\mathrm{ha}^{-1}$, respectivamente, para os híbridos Hyola 61, Hyola 76 e Hyola 433.

Para cada ensaio de uniformidade, com os dados de massa verde das 25UEB, foram determinados o coeficiente de autocorrelação espacial de primeira ordem $(\rho)$, a variância $\left(\mathrm{s}^{2}\right)$, a média (m) e o coeficiente de variação do ensaio $(\mathrm{CV})$, em percentagem. A estimativa de $\rho$ foi obtida no sentido das linhas, de acordo com Paranaíba et al. (2009). Para isso, iniciou-se o caminhamento a partir da UEB localizada na linha 1 , coluna 1 , até a linha 1 , coluna 5 , retornando a partir da linha 2, coluna 5, até a linha 2 , coluna 1 , e assim sucessivamente, até completar o caminhamento na UEB localizada na linha 5, coluna 5. Em cada um dos 27 ensaios, foi determinado o tamanho ótimo de parcela (Xo) pelo 
método da curvatura máxima do modelo do coeficiente de variação, pela expressão (Paranaíba et al., 2009)

$X o=\frac{10 \sqrt[3]{2\left(1-\rho^{2}\right) s^{2} m}}{m}$

A seguir, foi determinado o coeficiente de variação no tamanho ótimo de parcela $\left(\mathrm{CV}_{\mathrm{Xo}_{0}}\right)$, em percentagem, pela expressão (Paranaíba et al., 2009)

$C V_{X o}=\frac{\sqrt{\left(1-\rho^{2}\right) s^{2} / m^{2}}}{\sqrt{X o}} \times 100$

Dessa forma, para cada um dos híbridos, foram obtidas nove estimativas das estatísticas $\rho, s^{2}, \mathrm{~m}, \mathrm{CV}$, Xo e $\mathrm{CV}_{\mathrm{Xo}}$.

A partir das nove estimativas de cada estatística $\left(\rho, s^{2}\right.$, $\mathrm{m}$, CV, Xo e $\mathrm{CV}_{\mathrm{x}_{0}}$ ), de cada híbrido, foram calculadas a média, o desvio-padrão, o coeficiente de variação e o valor-p do teste de normalidade de Kolmogorov-Smirnov. A comparação das médias das estatísticas $\rho, s^{2}, \mathrm{~m}, \mathrm{CV}$, Xo e $\mathrm{CV}_{\mathrm{Xo}}$ entre os híbridos ( $\mathrm{n}=9$ ensaios de uniformidade por híbrido) foi realizada por meio do teste de Scott-Knott, a $5 \%$ de probabilidade.

A diferença mínima significativa (d) do teste de Tukey, expressa em percentagem da média do experimento, é estimada por

$d=\frac{q_{\alpha(i ; G L E)} \sqrt{\frac{Q M E}{r}}}{m} \times 100$

em que $q_{\alpha(i ; G L E)}$ é o valor crítico do teste de Tukey em nível $\alpha$ de probabilidade de erro ( $\alpha=0,05$, nesse estudo), i é o número de tratamentos, GLE é o número de graus de liberdade do erro, ou seja, $\mathrm{i}(\mathrm{r}-1)$ para o delineamento inteiramente casualizado e (i-1)(r-1) para o delineamento blocos ao acaso, QME é o quadrado médio do erro, r é o número de repetiçôes e $\mathrm{m}$ é a média do experimento.

Substituindo a expressão do coeficiente de variação experimental

$$
\left(C V=\frac{\sqrt{Q M E}}{m} \times 100\right)
$$

em percentagem, na expressão para o cálculo de d e isolando $r$ tem-se

$r=\left(\frac{q_{\alpha(i ; G L E)} C V}{d}\right)^{2}$

Nesse estudo, o CV é expresso em percentagem e corresponde ao $\mathrm{CV}_{\mathrm{Xo}}$, pois esse é o $\mathrm{CV}$ esperado para o experimento com o tamanho ótimo de parcela $(\mathrm{Xo})$ determinado. A seguir, a partir da maior média de $\mathrm{CV}_{\mathrm{Xo}_{\mathrm{o}}}$, entre os três híbridos, determinouse o número de repetiçôes (r), por processo iterativo até a convergência, para experimentos nos delineamentos inteiramente casualizados e blocos ao acaso, em cenários formados por combinaçóes de i (i=3, $4, \ldots, 50)$ e d (d=10\%, 13\%, ..., 40\%). Menores valores de $\mathrm{d}$ indicam maior precisão experimental, ou seja, menores diferenças entre médias de tratamentos serão consideradas significativas e vice-versa. As análises estatísticas foram realizadas com auxílio dos aplicativos Microsoft Office Excel $^{\circledR}$ e Genes (Cruz, 2013).

\section{RESULTADOS E DISCUSSÃO}

Os coeficientes de variação das estatísticas coeficiente de autocorrelaçáo espacial de primeira ordem $(\rho)$, variância $\left(\mathrm{s}^{2}\right)$, média $(\mathrm{m})$, coeficiente de variação do ensaio $(\mathrm{CV})$, tamanho ótimo de parcela (Xo) e coeficiente de variação no tamanho ótimo de parcela $\left(\mathrm{CV}_{\mathrm{Xo}}\right)$, obtidas a partir da massa verde de canola (Brassica napus L.), oscilaram entre $19,10 \%$ e $109,38 \%$ para o híbrido Hyola 61, entre 9,42\% e $100,06 \%$ para o híbrido Hyola 76 e entre 16,01\% e 68,44\% para o híbrido Hyola 433 (Tabela 1). Esse cenário de ampla variabilidade das estatísticas $\rho, s^{2}, \mathrm{~m}, \mathrm{CV}$, Xo e $\mathrm{CV}_{\mathrm{Xo}}$, entre ensaios de uniformidade, também foi constatado nas culturas de aveia-preta (Cargnelutti et al., 2014a) e feijão-de-porco (Cargnelutti et al., 2014b). Devido à ampla variação, pode-se inferir que esse conjunto de ensaios de uniformidade (nove ensaios de uniformidade para cada híbrido) é adequado para o estudo do dimensionamento de tamanho ótimo de parcela e número de repetiçóes, por contemplar cenários extremos de variabilidade.

De acordo com o teste de Kolmogorov-Smirnov, as estatísticas $\rho, s^{2}, \mathrm{~m}, \mathrm{CV}$, Xo e $\mathrm{CV}_{\mathrm{Xo}}$ apresentaram boa aderência à distribuição normal $(\mathrm{p} \geq 0,821$ no híbrido Hyola 61, $\mathrm{p} \geq 0,407$ no híbrido Hyola 76 e $\mathrm{p} \geq 0,446$ no híbrido Hyola 433) (Tabela 1), o que indica que a média é a medida de tendência central adequada para representar os nove ensaios de uniformidade, de cada híbrido. Assim, com base no teste de Scott-Knott, observou-se que o coeficiente de autocorrelação espacial de primeira ordem $(\rho)$ não diferiu entre os híbridos. Porém, foram constatadas diferenças entre os híbridos quanto à variância $\left(\mathrm{s}^{2}\right)$ e a média $(\mathrm{m})$. No método da curvatura máxima do modelo do coeficiente de variação (Paranaíba et al., 2009), o tamanho ótimo de parcela (Xo) e o coeficiente de variação no tamanho ótimo de parcela $\left(\mathrm{CV}_{\mathrm{Xo}_{\mathrm{o}}}\right)$ são calculados com base em $\rho, s^{2}$ e $\mathrm{m}$, o que explica as diferenças de $\mathrm{Xo} \mathrm{e}_{\mathrm{CV}}$ entre os híbridos (Tabela 1).

A média de massa verde de canola entre os híbridos decresceu na seguinte ordem: Hyola 76 (1.390,44 gramas $\left.\mathrm{m}^{-2}\right)$, Hyola $433\left(1.017,35\right.$ gramas $\left.\mathrm{m}^{-2}\right)$ e Hyola 61 $\left(570,25\right.$ gramas $\left.\mathrm{m}^{-2}\right)$ (Tabela 1$)$. Essas produçóes de massa verde de canola, desses três híbridos, foram inferiores as 14,20 t ha ${ }^{-1}$, obtidas no estudo de Pavinato et al. (1994). Diferenças de cultivar, clima, solo, manejo, época de semeadura e época de avaliação podem, provavelmente, explicar os resultados distintos entre essas pesquisas.

A média do coeficiente de variação do ensaio $(\mathrm{CV}=38,06 \%)$, do tamanho ótimo de parcela $\left(\mathrm{Xo}=6,41 \mathrm{~m}^{2}\right)$ e do coeficiente de variação no tamanho ótimo de parcela $\left(\mathrm{CV}_{\mathrm{Xo}_{\mathrm{o}}}=14,33 \%\right)$ dos nove ensaios de uniformidade com o híbrido Hyola 61 foi maior que as médias dos ensaios com os híbridos 
Tabela 1. Coeficiente de autocorrelação espacial de primeira ordem $(\rho)$, variância $\left(\mathrm{s}^{2}\right)$, média $(\mathrm{m})$, coeficiente de variação do ensaio $(\mathrm{CV}$, em \%), tamanho ótimo de parcela $\left(\mathrm{Xo}, \mathrm{em} \mathrm{m}^{2}\right)$ e coeficiente de variaçáo no tamanho ótimo de parcela $\left(\mathrm{CV}_{\mathrm{Xo}_{0}}\right.$, em \%), para a massa verde de canola (Brassica napus L.), em gramas por unidade experimental básica de $1 \mathrm{~m} \times 1 \mathrm{~m}\left(1 \mathrm{~m}^{2}\right)$, em 27 ensaios de uniformidade avaliados em três híbridos ( 9 ensaios por híbrido)

\begin{tabular}{|c|c|c|c|c|c|c|}
\hline $\begin{array}{l}\text { Ensaio(1) }^{(1)} \\
\text { estatística }\end{array}$ & $\rho$ & $s^{2}$ & m & CV (\%) & Xo $\left(m^{2}\right)$ & $\mathrm{CV}_{\mathrm{xo}}(\%)$ \\
\hline \multicolumn{7}{|c|}{ Hyola 61} \\
\hline 1 & 0,41 & $48.033,16$ & 473,92 & 46,25 & 7,09 & 15,86 \\
\hline 2 & 0,42 & $42.732,50$ & 463,20 & 44,63 & 6,91 & 15,44 \\
\hline 3 & 0,02 & $51.490,61$ & 403,12 & 56,29 & 8,59 & 19,20 \\
\hline 4 & 0,36 & $24.038,07$ & 522,36 & 29,68 & 5,35 & 11,96 \\
\hline 5 & 0,30 & $29.155,37$ & 656,04 & 26,03 & 4,97 & 11,12 \\
\hline 6 & 0,07 & $89.566,84$ & 703,52 & 42,54 & 7,12 & 15,91 \\
\hline 7 & 0,15 & $46.618,92$ & 686,56 & 31,45 & 5,79 & 12,94 \\
\hline 8 & $-0,12$ & $19.220,42$ & 581,56 & 23,84 & 4,82 & 10,78 \\
\hline 9 & 0,01 & $72.040,25$ & 642,00 & 41,81 & 7,04 & 15,75 \\
\hline Média ${ }^{(2)}$ & $0,18 a$ & $46.988,46 b$ & $570,25 c$ & $38,06 a$ & $6,41 \mathrm{a}$ & $14,33 a$ \\
\hline Desvio-padrão & 0,20 & $22.627,21$ & 108,91 & 10,83 & 1,25 & 2,79 \\
\hline $\begin{array}{l}\text { Coeficiente de } \\
\text { variação (\%) }\end{array}$ & 109,38 & 48,15 & 19,10 & 28,45 & 19,47 & 19,47 \\
\hline Valor-p ${ }^{(3)}$ & 0,937 & 0,869 & 0,903 & 0,898 & 0,821 & 0,821 \\
\hline \multicolumn{7}{|c|}{ Hyola 76} \\
\hline 1 & 0,19 & $144.646,99$ & $1.315,36$ & 28,91 & 5,44 & 12,17 \\
\hline 2 & 0,43 & $129.908,94$ & $1.554,76$ & 23,18 & 4,44 & 9,94 \\
\hline 3 & 0,18 & $186.609,84$ & $1.258,52$ & 34,32 & 6,11 & 13,67 \\
\hline 4 & $-0,03$ & $77.450,03$ & $1.329,12$ & 20,94 & 4,44 & 9,93 \\
\hline 5 & 0,18 & $212.560,25$ & $1.507,60$ & 30,58 & 5,66 & 12,65 \\
\hline 6 & 0,24 & $261.751,41$ & $1.333,64$ & 38,36 & 6,53 & 14,59 \\
\hline 7 & 0,06 & $74.751,82$ & $1.259,64$ & 21,71 & 4,54 & 10,16 \\
\hline 8 & 0,26 & $149.749,96$ & $1.608,28$ & 24,06 & 4,76 & 10,64 \\
\hline 9 & $-0,09$ & $115.576,50$ & $1.347,00$ & 25,24 & 5,02 & 11,22 \\
\hline Média ${ }^{(2)}$ & $0,16 a$ & $150.333,97 a$ & $1.390,44 a$ & $27,48 b$ & $5,22 b$ & $11,66 b$ \\
\hline Desvio-padrão & 0,16 & $61.527,00$ & 130,96 & 6,00 & 0,76 & 1,71 \\
\hline $\begin{array}{l}\text { Coeficiente de } \\
\text { variação (\%) }\end{array}$ & 100,06 & 40,93 & 9,42 & 21,85 & 14,64 & 14,64 \\
\hline Valor-p ${ }^{(3)}$ & 0,809 & 0,956 & 0,407 & 0,860 & 0,958 & 0,958 \\
\hline \multicolumn{7}{|c|}{ Hyola 433} \\
\hline 1 & 0,40 & $128.867,47$ & $1.072,84$ & 33,46 & 5,73 & 12,82 \\
\hline 2 & 0,53 & $166.679,01$ & $1.096,48$ & 37,23 & 5,83 & 13,04 \\
\hline 3 & 0,20 & $30.618,46$ & 607,04 & 28,83 & 5,42 & 12,13 \\
\hline 4 & 0,29 & $99.666,75$ & $1.305,60$ & 24,18 & 4,75 & 10,62 \\
\hline 5 & 0,14 & $100.739,06$ & $1.132,16$ & 28,03 & 5,36 & 11,99 \\
\hline 6 & 0,07 & $23.402,17$ & 627,60 & 24,38 & 4,91 & 10,98 \\
\hline 7 & 0,53 & $206.905,51$ & $1.578,56$ & 28,82 & 4,92 & 10,99 \\
\hline 8 & 0,24 & $261.239,57$ & $1.031,36$ & 49,56 & 7,74 & 17,31 \\
\hline 9 & 0,23 & $49.841,26$ & 704,52 & 31,69 & 5,75 & 12,87 \\
\hline Média $^{(2)}$ & $0,29 a$ & $118.662,14 a$ & $1.017,35 b$ & $31,80 \mathrm{~b}$ & $5,60 \mathrm{~b}$ & $12,53 b$ \\
\hline Desvio-padrão & 0,17 & $81.216,93$ & 323,82 & 7,85 & 0,90 & 2,01 \\
\hline $\begin{array}{l}\text { Coeficiente de } \\
\text { variação (\%) }\end{array}$ & 56,92 & 68,44 & 31,83 & 24,68 & 16,01 & 16,01 \\
\hline Valor-p ${ }^{(3)}$ & 0,914 & 0,993 & 0,921 & 0,852 & 0,446 & 0,446 \\
\hline
\end{tabular}

(1) Cada ensaio de uniformidade de tamanho $5 \mathrm{~m} \times 5 \mathrm{~m}\left(25 \mathrm{~m}^{2}\right)$ foi dividido em 25 unidades experimentais básicas de $1 \mathrm{~m} \times 1 \mathrm{~m}\left(1 \mathrm{~m}^{2}\right)$, formando uma matriz de cinco linhas e cinco colunas. ${ }^{(2)}$ Para cada estatística $\left(\rho, s^{2}, \mathrm{~m}, \mathrm{CV}, \mathrm{Xo}\right.$ e $\mathrm{CV}_{\mathrm{Xo}}$ ), as médias náo seguidas por mesma letra na coluna (comparaçáo de médias entre os híbridos) diferem a $5 \%$ de probabilidade pelo teste de Scott-Knott. ${ }^{(3)}$ Teste de normalidade de Kolmogorov-Smirnov. 
Hyola $76\left(\mathrm{CV}=27,48 \%, \mathrm{Xo}=5,22 \mathrm{~m}^{2}, \mathrm{CV}_{\mathrm{x}_{\mathrm{o}}}=11,66 \%\right)$ e Hyola $433\left(\mathrm{CV}=31,80 \%, \mathrm{Xo}=5,60 \mathrm{~m}^{2}, \mathrm{CV}_{\mathrm{Xo}_{\mathrm{o}}}=12,53 \%\right)$ (Tabela 1). Assim, pode-se inferir que o tamanho ótimo de parcela para avaliar a massa verde de canola foi de 6,41 unidades experimentais básicas de $1 \mathrm{~m}^{2}\left(6,41 \mathrm{~m}^{2}\right)$, e o coeficiente de variação no tamanho ótimo de parcela foi $14,33 \%$. Não foram encontrados estudos de tamanho ótimo de parcela para avaliar a massa verde de canola para serem comparados com os obtidos neste estudo. Porém, em outras plantas de cobertura de solo, como aveia-preta, para a avaliação da massa verde, Cargnelutti et al. (2014a) definiram Xo de 4,14m² e $\mathrm{CV}_{\mathrm{Xo}}$ de $9,25 \%$, e para a mensuração de massa verde de parte aérea de feijáo-de-porco, Cargnelutti et al. (2014b) estabeleceram Xo de 5,85 $\mathrm{m}^{2}$ e $\mathrm{CV}_{\mathrm{Xo}}$ de 13,09\%. Nesse contexto, pode-se verificar que, para a avaliação de massa verde de parte aérea dessas culturas, as estimativas de Xo e $\mathrm{CV}_{\mathrm{Xo}}$ foram próximas. Então, quando estas culturas são avaliadas no mesmo experimento, sugere-se dimensionar o tamanho de parcela com base na maior estimativa, a fim de garantir a precisão desejada para todas as culturas.

Os tamanhos de parcela utilizados por Bandeira et al. (2013), Castro \& Boaretto (2004), Kaefer et al. (2014), Krüger et al. (2011), Luz et al. (2013), foram superiores aos obtidos no presente estudo, sugerindo confiabilidade nas informaçôes publicadas. Por outro lado, Pavinato et al. (1994) e Sanches et al. (2014) utilizaram parcelas menores. A comparação entre o tamanho ótimo de parcela, obtido neste estudo, com os tamanhos de parcela utilizados nessas pesquisas, deve ser vista com cautela, pois há diferenças quanto à área da parcela efetivamente utilizada nas avaliaçôes, ao híbrido, à densidade de plantas, ao manejo e à presença de outras espécies, juntamente com a canola.

O número de repetições, para experimentos no delineamento inteiramente casualizado (DIC), em cenários formados por combinaçóes de i tratamentos $(i=3,4, \ldots$, 50) e d diferenças mínimas entre médias de tratamentos a serem detectadas como significativas a $5 \%$ de probabilidade, pelo teste de Tukey, expressas em percentagem da média do experimento $(\mathrm{d}=10 \%, 12 \%, \ldots, 40 \%)$, para avaliar a massa verde de canola, oscilou entre 2,62 (3 tratamentos e $\mathrm{d}=40 \%)$ e 65,60 (50 tratamentos e d=10\%) (Tabela 2). Já para experimentos no delineamento blocos ao acaso (DBA), o número de repetiçóes variou entre 2,17 (3 tratamentos e $\mathrm{d}=40 \%$ ) e 65,60 (50 tratamentos e $\mathrm{d}=10 \%$ ) (Tabela 3). Portanto, em experimentos com 50 tratamentos, mesmo com coeficiente de variação de $14,33 \%$, classificado como médio conforme Pimentel Gomes (2009), independentemente do delineamento experimental, obter precisão de $10 \%$ (maior precisão) é impraticável, pelo elevado número de repetições necessário (66 repetiçôes). O usuário das informaçôes deste estudo pode, a partir do tamanho ótimo de parcela $\left(\mathrm{Xo}_{\mathrm{o}}=6,41 \mathrm{~m}^{2}\right)$, estabelecer a relação entre $\mathrm{i}, \mathrm{d}$ e número de repetiçôes, possível de ser realizada. Embora, na prática, valores inteiros de número de repetições devam ser utilizados, os números de repetiçóes foram expressos com duas casas decimais (Tabelas 2 e 3) para evidenciar as diferenças entre as combinaçôes de i e d.

Independentemente do delineamento experimental (DIC ou DBA), para valores fixos de Xo, $\mathrm{CV}_{\mathrm{Xo}}$ e d, há aumento do número de repetiçóes (r) com o acréscimo do número de tratamentos (Tabelas 2 e 3). Como esperado, para valores fixos de $\mathrm{Xo}, \mathrm{CV}_{\mathrm{Xo}}$, i e d, são necessárias mais repetiçóes no DBA em relação ao DIC, o que comprova a maior eficiência do DIC em relação ao DBA, quando as unidades experimentais (parcelas) são homogêneas (Storck et al., 2011). Por exemplo, para $\mathrm{i}=3$ e $\mathrm{d}=10 \%$, precisariam 24,08 repetiçóes no DBA e 23,58 no DIC (Tabelas 2 e 3). Para o mesmo d, a diferença entre o número de repetiçóes entre os delineamentos DIC e DBA diminui com o acréscimo do número de tratamentos. Assim, quando o número de tratamentos é alto (i=50), o número de repetições para o DBA e para o DIC é próximo. Assim, por exemplo, para avaliar $\mathrm{i}=50$ com $\mathrm{d}=40 \%$, precisariam 4,26 repetiçóes nos dois delineamentos (DIC e DBA).

Como na prática não é possível realizar 4,26 repetiçôes em experimentos, deve ser escolhido número inteiro de repetiçôes. Assim, por exemplo, fixando-se $r$ igual a quatro repetiçóes, conforme utilizado nos experimentos de Bandeira et al. (2013), Castro \& Boaretto (2004), Kaefer et al. (2014), Krüger et al. (2011), Luz et al. (2013), Pavinato et al. (1994) e Sanches et al. (2014), a diferença mínima significativa (d) do teste de Tukey, expressa em percentagem da média do experimento, pode ser estimada pela expressão

$d=\frac{q_{\alpha(i ; G L E)} C V}{\sqrt{r}}$

Assim, com 50 tratamentos, para o delineamento inteiramente casualizado, ter-se-ia

$d=\frac{q_{5 \%(50 ; 150)} \times 14,33}{\sqrt{4}}=\frac{5,7710567 \times 14,33}{\sqrt{4}}=41,349 \%$

e para o delineamento blocos ao acaso

$d=\frac{q_{5 \%(50 ; 147)} \times 14,33}{\sqrt{4}}=\frac{5,7736023 \times 14,33}{\sqrt{4}}=41,367 \%$

Então, pode-se inferir que, para avaliar a massa verde de canola nos delineamentos inteiramente casualizados e blocos ao acaso com até 50 tratamentos, quatro repetiçóes são suficientes para identificar, como significativas a 5\% de probabilidade, pelo teste de Tukey, diferenças entre médias de tratamentos de $41,4 \%$ da média do experimento.

Estudos similares a esse para outros caracteres importantes de canola, como a produtividade de gráos e o teor de óleo, são sugeridos, pois não necessariamente o tamanho de parcela e o número de repetiçóes determinados para massa verde garantem a precisão experimental desejada para os demais caracteres. Porém, para percentual fixo de massa seca em relaçâo à massa verde, em todas as unidades experimentais 
Tabela 2. Número de repetiçôes, para experimentos no delineamento inteiramente casualizado, em cenários formados pelas combinaçôes de i tratamentos $(\mathrm{i}=3,4, \ldots, 50)$ e d diferenças mínimas entre médias de tratamentos a serem detectadas como significativas a $5 \%$ de probabilidade, pelo teste de Tukey, expressas em percentagem da média do experimento $(\mathrm{d}=10 \%, 13 \%, \ldots, 40 \%)$, para avaliar a massa verde de canola (Brassica napus L.) a partir de tamanho ótimo de parcela $\left(\mathrm{Xo}_{\mathrm{o}}=6,41 \mathrm{~m}^{2}\right)$ e coeficiente de variação no tamanho ótimo de parcela $\left(\mathrm{CV}_{\mathrm{Xo}_{\mathrm{o}}}=14,33 \%\right)$

\begin{tabular}{|c|c|c|c|c|c|c|c|c|c|c|c|}
\hline $\mathbf{i}$ & $10 \%$ & $13 \%$ & $16 \%$ & $19 \%$ & $22 \%$ & $25 \%$ & $28 \%$ & $31 \%$ & $34 \%$ & $37 \%$ & $40 \%$ \\
\hline 3 & 23,58 & 14,39 & 9,88 & 7,34 & 5,78 & 4,76 & 4,05 & 3,53 & 3,17 & 2,98 & 2,62 \\
\hline 4 & 27,97 & 16,91 & 11,48 & 8,42 & 6,53 & 5,30 & 4,44 & 3,83 & 3,38 & 3,04 & 2,79 \\
\hline 5 & 31,31 & 18,84 & 12,71 & 9,25 & 7,12 & 5,72 & 4,75 & 4,05 & 3,54 & 3,16 & 2,86 \\
\hline 6 & 34,01 & 20,41 & 13,71 & 9,93 & 7,60 & 6,07 & 5,00 & 4,24 & 3,68 & 3,25 & 2,93 \\
\hline 7 & 36,30 & 21,73 & 14,56 & 10,51 & 8,02 & 6,37 & 5,23 & 4,41 & 3,80 & 3,34 & 2,99 \\
\hline 8 & 38,27 & 22,87 & 15,30 & 11,02 & 8,38 & 6,63 & 5,43 & 4,56 & 3,91 & 3,43 & 3,05 \\
\hline 9 & 40,01 & 23,89 & 15,95 & 11,47 & 8,70 & 6,87 & 5,60 & 4,69 & 4,02 & 3,51 & 3,11 \\
\hline 10 & 41,57 & 24,79 & 16,53 & 11,87 & 8,99 & 7,09 & 5,77 & 4,82 & 4,11 & 3,58 & 3,16 \\
\hline 11 & 42,98 & 25,61 & 17,06 & 12,24 & 9,25 & 7,28 & 5,91 & 4,93 & 4,20 & 3,64 & 3,21 \\
\hline 12 & 44,27 & 26,36 & 17,55 & 12,57 & 9,50 & 7,46 & 6,05 & 5,03 & 4,28 & 3,71 & 3,26 \\
\hline 13 & 45,45 & 27,06 & 18,00 & 12,88 & 9,72 & 7,63 & 6,18 & 5,13 & 4,36 & 3,77 & 3,31 \\
\hline 14 & 46,55 & 27,70 & 18,41 & 13,17 & 9,93 & 7,79 & 6,30 & 5,22 & 4,43 & 3,82 & 3,35 \\
\hline 15 & 47,58 & 28,30 & 18,80 & 13,44 & 10,13 & 7,93 & 6,41 & 5,31 & 4,50 & 3,87 & 3,39 \\
\hline 16 & 48,53 & 28,86 & 19,17 & 13,70 & 10,31 & 8,07 & 6,52 & 5,39 & 4,56 & 3,93 & 3,43 \\
\hline 17 & 49,44 & 29,38 & 19,51 & 13,93 & 10,48 & 8,20 & 6,62 & 5,47 & 4,62 & 3,97 & 3,47 \\
\hline 18 & 50,29 & 29,88 & 19,83 & 14,16 & 10,65 & 8,32 & 6,71 & 5,55 & 4,68 & 4,02 & 3,51 \\
\hline 19 & 51,09 & 30,35 & 20,14 & 14,37 & 10,80 & 8,44 & 6,80 & 5,62 & 4,74 & 4,06 & 3,54 \\
\hline 20 & 51,85 & 30,80 & 20,43 & 14,58 & 10,95 & 8,55 & 6,89 & 5,69 & 4,79 & 4,11 & 3,58 \\
\hline 21 & 52,58 & 31,23 & 20,71 & 14,77 & 11,09 & 8,66 & 6,97 & 5,75 & 4,84 & 4,15 & 3,61 \\
\hline 22 & 53,28 & 31,63 & 20,97 & 14,95 & 11,23 & 8,76 & 7,05 & 5,81 & 4,89 & 4,19 & 3,64 \\
\hline 23 & 53,94 & 32,02 & 21,23 & 15,13 & 11,36 & 8,86 & 7,13 & 5,87 & 4,94 & 4,23 & 3,67 \\
\hline 24 & 54,57 & 32,39 & 21,47 & 15,30 & 11,48 & 8,95 & 7,20 & 5,93 & 4,98 & 4,26 & 3,70 \\
\hline 25 & 55,18 & 32,75 & 21,70 & 15,46 & 11,60 & 9,05 & 7,27 & 5,99 & 5,03 & 4,30 & 3,73 \\
\hline 26 & 55,77 & 33,10 & 21,93 & 15,62 & 11,72 & 9,13 & 7,34 & 6,04 & 5,07 & 4,33 & 3,76 \\
\hline 27 & 56,34 & 33,43 & 22,15 & 15,77 & 11,83 & 9,22 & 7,40 & 6,09 & 5,11 & 4,37 & 3,79 \\
\hline 28 & 56,88 & 33,75 & 22,35 & 15,92 & 11,93 & 9,30 & 7,47 & 6,14 & 5,15 & 4,40 & 3,81 \\
\hline 29 & 57,41 & 34,05 & 22,56 & 16,06 & 12,04 & 9,38 & 7,53 & 6,19 & 5,19 & 4,43 & 3,84 \\
\hline 30 & 57,91 & 34,35 & 22,75 & 16,20 & 12,14 & 9,45 & 7,59 & 6,24 & 5,23 & 4,46 & 3,86 \\
\hline 31 & 58,40 & 34,64 & 22,94 & 16,33 & 12,24 & 9,53 & 7,64 & 6,28 & 5,27 & 4,49 & 3,89 \\
\hline 32 & 58,88 & 34,92 & 23,12 & 16,46 & 12,33 & 9,60 & 7,70 & 6,33 & 5,30 & 4,52 & 3,91 \\
\hline 33 & 59,34 & 35,19 & 23,30 & 16,58 & 12,42 & 9,67 & 7,75 & 6,37 & 5,34 & 4,55 & 3,93 \\
\hline 34 & 59,79 & 35,46 & 23,47 & 16,70 & 12,51 & 9,74 & 7,81 & 6,41 & 5,37 & 4,58 & 3,96 \\
\hline 35 & 60,23 & 35,71 & 23,64 & 16,82 & 12,60 & 9,80 & 7,86 & 6,45 & 5,40 & 4,60 & 3,98 \\
\hline 36 & 60,65 & 35,96 & 23,80 & 16,93 & 12,68 & 9,87 & 7,91 & 6,49 & 5,44 & 4,63 & 4,00 \\
\hline 37 & 61,06 & 36,20 & 23,96 & 17,04 & 12,76 & 9,93 & 7,96 & 6,53 & 5,47 & 4,66 & 4,02 \\
\hline 38 & 61,46 & 36,44 & 24,11 & 17,15 & 12,84 & 9,99 & 8,00 & 6,57 & 5,50 & 4,68 & 4,04 \\
\hline 39 & 61,85 & 36,67 & 24,26 & 17,26 & 12,92 & 10,05 & 8,05 & 6,61 & 5,53 & 4,71 & 4,06 \\
\hline 40 & 62,23 & 36,89 & 24,41 & 17,36 & 13,00 & 10,11 & 8,10 & 6,64 & 5,56 & 4,73 & 4,08 \\
\hline 41 & 62,60 & 37,11 & 24,55 & 17,46 & 13,07 & 10,16 & 8,14 & 6,68 & 5,59 & 4,75 & 4,10 \\
\hline 42 & 62,97 & 37,32 & 24,69 & 17,56 & 13,14 & 10,22 & 8,18 & 6,71 & 5,61 & 4,78 & 4,12 \\
\hline 43 & 63,32 & 37,53 & 24,83 & 17,66 & 13,21 & 10,27 & 8,23 & 6,75 & 5,64 & 4,80 & 4,14 \\
\hline 44 & 63,67 & 37,74 & 24,96 & 17,75 & 13,28 & 10,32 & 8,27 & 6,78 & 5,67 & 4,82 & 4,16 \\
\hline 45 & 64,01 & 37,93 & 25,10 & 17,84 & 13,35 & 10,38 & 8,31 & 6,81 & 5,70 & 4,84 & 4,18 \\
\hline 46 & 64,34 & 38,13 & 25,22 & 17,93 & 13,42 & 10,43 & 8,35 & 6,84 & 5,72 & 4,86 & 4,19 \\
\hline 47 & 64,66 & 38,32 & 25,35 & 18,02 & 13,48 & 10,48 & 8,39 & 6,87 & 5,75 & 4,88 & 4,21 \\
\hline 48 & 64,98 & 38,51 & 25,47 & 18,11 & 13,54 & 10,52 & 8,42 & 6,91 & 5,77 & 4,90 & 4,23 \\
\hline 49 & 65,29 & 38,69 & 25,59 & 18,19 & 13,61 & 10,57 & 8,46 & 6,94 & 5,80 & 4,92 & 4,24 \\
\hline 50 & 65,60 & 38,87 & 25,71 & 18,27 & 13,67 & 10,62 & 8,50 & 6,96 & 5,82 & 4,94 & 4,26 \\
\hline
\end{tabular}


Tabela 3. Número de repetições, para experimentos no delineamento blocos ao acaso, em cenários formados pelas combinaçôes de i tratamentos (i=3, 4, .., 50) e d diferenças mínimas entre médias de tratamentos a serem detectadas como significativas a 5\% de probabilidade, pelo teste de Tukey, expressas em percentagem da média do experimento $(\mathrm{d}=10 \%, 13 \%, \ldots, 40 \%)$, para avaliar a massa verde de canola (Brassica napus $\mathrm{L}$.) a partir de tamanho ótimo de parcela $\left(\mathrm{Xo}=6,41 \mathrm{~m}^{2}\right)$ e coeficiente de variação no tamanho ótimo de parcela $\left(\mathrm{CV}_{\mathrm{X}_{\mathrm{o}}}=14,33 \%\right)$

\begin{tabular}{|c|c|c|c|c|c|c|c|c|c|c|c|}
\hline $\mathbf{i}$ & $10 \%$ & $13 \%$ & $16 \%$ & $19 \%$ & $22 \%$ & $25 \%$ & $28 \%$ & $31 \%$ & $34 \%$ & $37 \%$ & $40 \%$ \\
\hline 3 & 24,08 & 14,89 & 10,37 & 7,83 & 6,26 & 5,23 & 4,51 & 3,91 & 3,28 & 2,64 & 2,17 \\
\hline 4 & 28,25 & 17,20 & 11,76 & 8,70 & 6,82 & 5,57 & 4,72 & 4,09 & 3,64 & 3,26 & 2,99 \\
\hline 5 & 31,49 & 19,02 & 12,89 & 9,44 & 7,31 & 5,90 & 4,93 & 4,24 & 3,72 & 3,33 & 3,03 \\
\hline 6 & 34,14 & 20,54 & 13,84 & 10,07 & 7,74 & 6,20 & 5,14 & 4,38 & 3,81 & 3,38 & 3,05 \\
\hline 7 & 36,39 & 21,83 & 14,66 & 10,62 & 8,12 & 6,47 & 5,33 & 4,51 & 3,90 & 3,45 & 3,09 \\
\hline 8 & 38,35 & 22,95 & 15,37 & 11,10 & 8,46 & 6,71 & 5,51 & 4,64 & 4,00 & 3,51 & 3,13 \\
\hline 9 & 40,07 & 23,95 & 16,01 & 11,53 & 8,76 & 6,94 & 5,67 & 4,76 & 4,08 & 3,57 & 3,17 \\
\hline 10 & 41,62 & 24,84 & 16,59 & 11,92 & 9,04 & 7,14 & 5,82 & 4,87 & 4,16 & 3,63 & 3,22 \\
\hline 11 & 43,02 & 25,66 & 17,11 & 12,28 & 9,30 & 7,33 & 5,96 & 4,97 & 4,24 & 3,69 & 3,26 \\
\hline 12 & 44,30 & 26,40 & 17,59 & 12,61 & 9,53 & 7,50 & 6,09 & 5,07 & 4,32 & 3,75 & 3,30 \\
\hline 13 & 45,48 & 27,09 & 18,03 & 12,92 & 9,75 & 7,66 & 6,21 & 5,17 & 4,39 & 3,80 & 3,34 \\
\hline 14 & 46,58 & 27,73 & 18,44 & 13,20 & 9,96 & 7,82 & 6,33 & 5,25 & 4,46 & 3,85 & 3,38 \\
\hline 15 & 47,60 & 28,32 & 18,83 & 13,47 & 10,15 & 7,96 & 6,44 & 5,34 & 4,52 & 3,90 & 3,42 \\
\hline 16 & 48,56 & 28,88 & 19,19 & 13,72 & 10,33 & 8,09 & 6,54 & 5,42 & 4,58 & 3,95 & 3,46 \\
\hline 17 & 49,45 & 29,40 & 19,53 & 13,95 & 10,50 & 8,22 & 6,64 & 5,49 & 4,64 & 4,00 & 3,49 \\
\hline 18 & 50,30 & 29,90 & 19,85 & 14,18 & 10,67 & 8,34 & 6,73 & 5,57 & 4,70 & 4,04 & 3,53 \\
\hline 19 & 51,11 & 30,37 & 20,16 & 14,39 & 10,82 & 8,46 & 6,82 & 5,63 & 4,75 & 4,08 & 3,56 \\
\hline 20 & 51,87 & 30,81 & 20,45 & 14,59 & 10,97 & 8,57 & 6,90 & 5,70 & 4,81 & 4,12 & 3,59 \\
\hline 21 & 52,59 & 31,24 & 20,72 & 14,78 & 11,11 & 8,67 & 6,98 & 5,76 & 4,86 & 4,16 & 3,62 \\
\hline 22 & 53,29 & 31,64 & 20,99 & 14,97 & 11,24 & 8,78 & 7,06 & 5,83 & 4,90 & 4,20 & 3,66 \\
\hline 23 & 53,95 & 32,03 & 21,24 & 15,14 & 11,37 & 8,87 & 7,14 & 5,88 & 4,95 & 4,24 & 3,69 \\
\hline 24 & 54,58 & 32,40 & 21,48 & 15,31 & 11,49 & 8,97 & 7,21 & 5,94 & 5,00 & 4,28 & 3,71 \\
\hline 25 & 55,19 & 32,76 & 21,71 & 15,47 & 11,61 & 9,06 & 7,28 & 6,00 & 5,04 & 4,31 & 3,74 \\
\hline 26 & 55,78 & 33,10 & 21,94 & 15,63 & 11,73 & 9,14 & 7,35 & 6,05 & 5,08 & 4,34 & 3,77 \\
\hline 27 & 56,34 & 33,43 & 22,15 & 15,78 & 11,84 & 9,23 & 7,41 & 6,10 & 5,12 & 4,38 & 3,80 \\
\hline 28 & 56,89 & 33,75 & 22,36 & 15,93 & 11,94 & 9,31 & 7,47 & 6,15 & 5,16 & 4,41 & 3,82 \\
\hline 29 & 57,41 & 34,06 & 22,56 & 16,07 & 12,05 & 9,38 & 7,53 & 6,20 & 5,20 & 4,44 & 3,85 \\
\hline 30 & 57,92 & 34,36 & 22,76 & 16,20 & 12,15 & 9,46 & 7,59 & 6,24 & 5,24 & 4,47 & 3,87 \\
\hline 31 & 58,41 & 34,65 & 22,95 & 16,34 & 12,24 & 9,53 & 7,65 & 6,29 & 5,27 & 4,50 & 3,89 \\
\hline 32 & 58,89 & 34,93 & 23,13 & 16,46 & 12,34 & 9,60 & 7,71 & 6,33 & 5,31 & 4,53 & 3,92 \\
\hline 33 & 59,35 & 35,20 & 23,31 & 16,59 & 12,43 & 9,67 & 7,76 & 6,38 & 5,34 & 4,56 & 3,94 \\
\hline 34 & 59,80 & 35,46 & 23,48 & 16,71 & 12,52 & 9,74 & 7,81 & 6,42 & 5,38 & 4,58 & 3,96 \\
\hline 35 & 60,23 & 35,72 & 23,64 & 16,83 & 12,60 & 9,81 & 7,86 & 6,46 & 5,41 & 4,61 & 3,99 \\
\hline 36 & 60,65 & 35,97 & 23,81 & 16,94 & 12,69 & 9,87 & 7,91 & 6,50 & 5,44 & 4,64 & 4,01 \\
\hline 37 & 61,07 & 36,21 & 23,97 & 17,05 & 12,77 & 9,93 & 7,96 & 6,54 & 5,47 & 4,66 & 4,03 \\
\hline 38 & 61,47 & 36,44 & 24,12 & 17,16 & 12,85 & 9,99 & 8,01 & 6,57 & 5,50 & 4,69 & 4,05 \\
\hline 39 & 61,86 & 36,67 & 24,27 & 17,26 & 12,92 & 10,05 & 8,06 & 6,61 & 5,53 & 4,71 & 4,07 \\
\hline 40 & 62,24 & 36,90 & 24,42 & 17,37 & 13,00 & 10,11 & 8,10 & 6,65 & 5,56 & 4,73 & 4,09 \\
\hline 41 & 62,61 & 37,11 & 24,56 & 17,47 & 13,07 & 10,17 & 8,14 & 6,68 & 5,59 & 4,76 & 4,11 \\
\hline 42 & 62,97 & 37,33 & 24,70 & 17,56 & 13,15 & 10,22 & 8,19 & 6,72 & 5,62 & 4,78 & 4,12 \\
\hline 43 & 63,33 & 37,54 & 24,83 & 17,66 & 13,22 & 10,28 & 8,23 & 6,75 & 5,65 & 4,80 & 4,14 \\
\hline 44 & 63,67 & 37,74 & 24,97 & 17,75 & 13,29 & 10,33 & 8,27 & 6,78 & 5,67 & 4,82 & 4,16 \\
\hline 45 & 64,01 & 37,94 & 25,10 & 17,85 & 13,35 & 10,38 & 8,31 & 6,82 & 5,70 & 4,85 & 4,18 \\
\hline 46 & 64,34 & 38,13 & 25,23 & 17,94 & 13,42 & 10,43 & 8,35 & 6,85 & 5,73 & 4,87 & 4,20 \\
\hline 47 & 64,66 & 38,32 & 25,35 & 18,02 & 13,48 & 10,48 & 8,39 & 6,88 & 5,75 & 4,89 & 4,21 \\
\hline 48 & 64,98 & 38,51 & 25,47 & 18,11 & 13,55 & 10,53 & 8,43 & 6,91 & 5,77 & 4,91 & 4,23 \\
\hline 49 & 65,29 & 38,69 & 25,59 & 18,19 & 13,61 & 10,58 & 8,46 & 6,94 & 5,80 & 4,93 & 4,25 \\
\hline 50 & 65,60 & 38,87 & 25,71 & 18,28 & 13,67 & 10,62 & 8,50 & 6,97 & 5,82 & 4,95 & 4,26 \\
\hline
\end{tabular}


básicas, como exemplo $10 \%$ da massa verde é massa seca, o tamanho de parcela e o número de repetições determinados para massa verde serão os mesmos para massa seca.

\section{CONCLUSÃO}

O tamanho ótimo de parcela para avaliar a massa verde de canola é de $6,41 \mathrm{~m}^{2}$. Quatro repetiçôes, para avaliar até 50 tratamentos, nos delineamento inteiramente casualizado e blocos ao acaso, são suficientes para identificar, como significativas a 5\% de probabilidade, pelo teste de Tukey, diferenças entre médias de tratamentos de 41,4\% da média do experimento.

\section{AGRADECIMENTOS}

Ao Conselho Nacional de Desenvolvimento Científico e Tecnológico (CNPq) e à Coordenação de Aperfeiçoamento de Pessoal de Nível Superior (CAPES), pelas bolsas concedidas. Aos alunos bolsistas e voluntários, pelo auxílio na coleta de dados. Ao pesquisador da Embrapa, Gilberto Omar Tomm, pela cedência das sementes de canola (Brassica napus L.).

\section{REFERÊNCIAS}

Bandeira, T. P., Chavarria, G., \& Tomm, G. O. (2013). Desempenho agronômico de canola em diferentes espaçamentos entre linhas e densidades de plantas. Pesquisa Agropecuaria Brasileira, 48, 13321341. http://dx.doi.org/10.1590/S0100-204X2013001000004.

Cargnelutti, A., Fo., Alves, B. M., Toebe, M., Burin, C., Santos, G. O., Facco, G., Neu, I. M. M., \& Stefanello, R. B. (2014a). Tamanho de parcela e número de repetições em aveia preta. Ciência Rural, 44, 1732-1739. http://dx.doi.org/10.1590/0103-8478cr20131466.

Cargnelutti, A., Fo., Toebe, M., Burin, C., Alves, B. M., Neu, I. M. M., Casarotto, G., \& Facco, G. (2014b). Tamanho de parcela e número de repetições em feijão de porco. Ciência Rural, 44, 2142-2150. Recuperado de http://coral.ufsm.br/ccrrevista/artigos/cr-2014-0317.pdf

Castro, A. M. C., \& Boaretto, A. E. (2004). Teores e acúmulo de nutrientes em função da população de plantas de canola. Scientia Agraria, 5, 95-101. Recuperado de http://ojs.c3sl.ufpr.br/ojs/index. php/agraria/article/view/1103/920

Cruz, C. D. (2013). GENES: a software package for analysis in experimental statistics and quantitative genetics. Acta Scientiarum Agronomy, 35, 271-276. http://dx.doi.org/10.4025/actasciagron. v35i3.21251.
Heldwein, A. B., Buriol, G. A., \& Streck, N. A. (2009). O clima de Santa Maria. Ciência \& Ambiente, 38, 43-58.

Kaefer, J. E., Guimarães, V. F., Richart, A., Tomm, G. O., \& Müller, A. L. (2014). Produtividade de grãos e componentes de produção da canola de acordo com fontes e doses de nitrogênio. Pesquisa Agropecuaria Brasileira, 49, 273-280. http://dx.doi.org/10.1590/ S0100-204X2014000400005.

Krüger, C. A. M. B., Silva, J. A. G., Medeiros, S. L. P., Dalmago, G. A., Sartori, C. O., \& Schiavo, J. (2011). Arranjo de plantas na expressáo dos componentes da produtividade de gráos de canola. Pesquisa Agropecuaria Brasileira, 46, 1448-1453. http://dx.doi. org/10.1590/S0100-204X2011001100005.

Luz, G. L., Brunetto, S. P., Meneghini, A. L., Petri, G., Carpenedo, M. C., \& Nesello, R. (2013). Produtividade de cinco híbridos de canola em Xanxerê, SC. Unoesc \& Ciência, 4, 7-12. Recuperado de http://editora.unoesc.edu.br/index.php/acet/article/view/2663/pdf

Mori, C., Tomm, G. O., \& Ferreira, P. E. P. (2014). Aspectos econômicos e conjunturais da cultura da canola no mundo e no Brasil (Embrapa Trigo. Documentos, 149). Passo Fundo: Embrapa Trigo. 36 p. Recuperado de http://www.cnpt.embrapa.br/biblio/ do/p_do149.htm

Paranaíba, P. F., Ferreira, D. F., \& Morais, A. R. (2009). Tamanho ótimo de parcelas experimentais: proposição de métodos de estimação. Revista Brasileira de Biometria, 27, 255-268. Recuperado de http:// jaguar.fcav.unesp.br/RME/fasciculos/v27/v27_n2/Patricia.pdf

Pavinato, A., Aita, C., Ceretta, C. A., \& Bevilaqua, G. P. (1994). Resíduos culturais de espécies de inverno e o rendimento de grãos de milho no sistema de cultivo mínimo. Pesquisa Agropecuaria Brasileira, 29, 1427-1432. Recuperado de https://seer.sct.embrapa.br/index. php/pab/article/viewFile/4192/1483

Pimentel Gomes, F. (2009). Curso de estatística experimental (15. ed.). Piracicaba: FEALQ. 451 p.

Sanches, A. C., Gomes, E. P., Ramos, W. B., Mauad, M., Santos, S., \& Biscaro, G. A. (2014). Produtividade da canola sob irrigação e doses de adubação nitrogenada. Revista Brasileira de Engenharia Agrícola e Ambiental, 18, 688-693. http://dx.doi.org/10.1590/ S1415-43662014000700003.

Santos, H. G., Jacomine, P. K. T., Anjos, L. H. C., Oliveira, V. A., Oliveira, J. B., Coelho, M. R., Lumbreras, J. F., \& Cunha, T. J. F. (2006). Sistema brasileiro de classificação de solos. (2. ed.). Rio de Janeiro: Embrapa Solos. 306 p.

Storck, L., Garcia, D. C., Lopes, S. J., \& Estefanel, V. (2011). Experimentação vegetal. 3. (ed.). Santa Maria: UFSM. 200 p.

Tomm, G. O., Wiethölter, S., Dalmago, G. A., \& Santos, H. P. (2009). Tecnologia para produçáo de canola no Rio Grande do Sul (Embrapa Trigo. Documentos, 92). Passo Fundo: Embrapa Trigo. 41 p. Recuperado de http://www.cnpt.embrapa.br/biblio/do/p_do113.htm 